\title{
Ingestion of Raffinose Promotes Calcium Absorption in the Large Intestine of Rats
}

\author{
Rieko Mitamura, Hiroshi Hara, ${ }^{\dagger}$ and Yoritaka Aoyama \\ Division of Applied Bioscience, Graduate School of Agriculture, Hokkaido University, \\ Kita-9, Nishi-9, Kita-ku, Sapporo 060-8589, Japan
}

Received September 2, 2003; Accepted October 26, 2003

We examined the effects of feeding raffinose on intestinal calcium absorption in ovariectomized rats by two separate experiments. In experiment 1, female Sprague-Dawley rats (6 wk old) were divided into two groups: sham operation and ovariectomy, and fed diets with or without raffinose $(30 \mathrm{~g} / \mathrm{kg}$ diet $)$ for $4 \mathrm{wk}$. In experiment 2, ovariectomized rats with cecocolonectomy or transsection and reanastomosis (sham) were divided into two groups as in experiment 1 and fed the same diets for 3 wk. In experiment 1, calcium absorption was lower in the ovariectomized rats than in the sham rats but calcium absorption in rats fed the raffinose diet was higher than that in rats fed the raffinose-free diet. In experiment 2 , increased calcium absorption in the raffinose group was abolished by cecocolonectomy. The impaired absorption in ovariectomized rats was restored by feeding raffinose. The large intestine is involved in the beneficial effects of raffinose.

Key words: raffinose; calcium absorption; ovariectomy; rats

Estrogen deficiency and declining calcium absorption are important factors in the pathogenesis of age-related bone loss. Guidelines for dietary calcium intake have been proposed for minimizing the risk of osteoporosis; ${ }^{1,2)}$ however, the calcium intake in Japan is lower than the dietary reference intake of calcium. ${ }^{3,4)}$ The recommended dietary allowance of calcium for Japanese adults is $600 \mathrm{mg} / \mathrm{day}$, and the calcium requirement for elderly Japanese women was estimated by balance study to be $788 \mathrm{mg} /$ day. ${ }^{4)}$ Mean intake of calcium in Japan $(547 \mathrm{mg} /$ day $)$ has not reached the recommended dietary allowance. Moreover, women with postmenopausal osteoporosis are particularly susceptible to impaired calcium absorption.

It has been reported that calcium balance was decreased in ovariectomized (OVX) rats by increase in intestinal calcium secretion and by decrease in intestinal calcium absorption, and that these were the result of decreased levels of estrogen.5) Holzherr et al. ${ }^{6)}$ and $\mathrm{Kalu}^{7)}$ reported similar observations in human and animals, and our previous report also agreed with these results that ovarian hormone deficiency impaired ability of calcium absorption in rats everted intestinal sacs. $\left.{ }^{8}\right)$ The presence of estrogen receptors in rat duodenal cells were confirmed and estrogen stimulates intestinal calcium absorption via an estrogen receptor. ${ }^{9)}$ In cases with lower calcium intake and insufficient calcium absorption in the small intestine such as postmenopausal women, calcium absorption in the large intestine is important to maintain calcium homeostasis. ${ }^{10)}$

Several reports have indicated that the ingestion of fermentable dietary fibers ${ }^{11-14)}$ and oligosaccharides ${ }^{15,16)}$ increased calcium absorption in rats, and that the large intestine was involved in this beneficial effect. ${ }^{16,17)}$ Basically, dietary fibers and oligosaccharaides are presumably not absorbed in the small intestine but metabolized by the bacterial flora in the large intestine. Some studies have suggested that microbial fermentation products of indigestible saccharides are responsible for the increase of calcium absorption in the large intestine. ${ }^{18,19)}$

Raffinose, which is a trisaccharide composed of galactose, glucose, and fructose ( $\beta$-D-fructofuranosyl$O$ - $\alpha$-D-galactopyranosyl-(1,6)- $\alpha$-D-glucopyranoside), is an indigestible oligosaccharide that is distributed in plants such as sugar beet and soybean. It has been reported that administration of raffinose increased the fecal bifidobacteria and improved defecation in humans. ${ }^{20)}$ On the other hand, raffinose has been fermented by colonic microorganisms to produce short-chain fatty acids (SCFA), ${ }^{21)}$ from which it is expected for raffinose to increase calcium absorption in the large intestine. However, little is known about effects of raffinose on calcium absorption. In a previous study, we reported that raffinose promoted calcium absorption in normal rats and in vitro. ${ }^{21,22)}$ However, it has not been clarified whether raffinose improves ovariectomy-induced calcium malabsorption in rats.

The aim of this study was to evaluate the promotive

\footnotetext{
$\dagger$ To whom correspondence should be addressed. Tel: +81-11-706-3352; Fax: +81-11-706-2504; E-mail: hara@chem.agr.hokudai.ac.jp Abbreviations: OVX, ovariectomy; SCFA, short-chain fatty acids
} 
$(P<0.05)$. All statistical analyses were done using SPSS for Windows, Version 10.0 J (SPSS, Chicago, IL).

\section{Results}

\section{Experiment 1}

The mean final body weight was greater in OVX rats than in the sham-operated rats despite there being no differences in food intake between groups (Table 2). The uterine weight was much lower in the OVX rats than in the sham rats (Table 2). The uterine weight of one rat in the OVX group was as large as that in the sham group and we excluded this rat from the OVX group.

The calcium absorption rate of the control diet group but not of the raffinose-fed group was lower in OVX rats than that in sham rats (Fig. 1A). As for the calcium absorption rate, we did a multiple-range test since both treatment and diet were significantly different. The

Table 2. Final Body Weights, Food Intake and Uterine Weight (experiment 1)

\begin{tabular}{lrccc}
\hline \hline & $n$ & $\begin{array}{c}\text { Final body } \\
\text { weight }\end{array}$ & $\begin{array}{c}\text { Food } \\
\text { intake }\end{array}$ & Uterine weight \\
& & $g$ & $g /$ day & $m g / 100 g$ body weight \\
Sham & 10 & $279 \pm 5.5$ & $18.4 \pm 0.34$ & $211 \pm 19.0$ \\
$\quad$ Control & 10 & $270 \pm 6.5$ & $18.3 \pm 0.42$ & $204 \pm 14.5$ \\
$\quad$ Raffinose & & & & \\
OVX & 9 & $294 \pm 3.3$ & $18.1 \pm 0.02$ & $32 \pm 1.7$ \\
Control & 10 & $297 \pm 3.5$ & $18.2 \pm 0.01$ & $31 \pm 0.9$ \\
$\quad$ Raffinose & & & & \\
$P$ values & & $<0.001$ & 0.493 & $<0.001$ \\
$\quad$ Operation & & 0.455 & 0.668 & 0.677 \\
$\quad$ Diet & & 0.176 & 0.856 & 0.701 \\
$\quad$ Operation $\times$ diet & & & &
\end{tabular}

Each value represents means \pm SEM.

OVX, ovariectomy. absorption rates in the raffinose groups were higher than those in the control groups in both the sham and OVX rats. Moreover, the calcium absorption rate in OVX rats fed the raffinose diet was similar to those in the sham groups. Ovariectomy did not influence the magnesium absorption rate; however, the absorption rates were higher in the raffinose groups than in the control groups in both the sham and OVX rats (Fig. 1B).

In the OVX rats, the weight of the cecal wall and contents was greater than those in the sham rats (Table 3). In both the sham and OVX rats, the weight of the cecal wall and contents in the raffinose groups were much greater than those in the control groups. Cecal $\mathrm{pH}$ values in rats fed the raffinose diet were lower than those in rats fed the control diet. Ovariectomy did not influence the $\mathrm{pH}$ values. The total calcium pool in the cecal contents of OVX rats, especially in rats fed the control diet, was much higher than that of sham rats

Table 3. Weight of the Fresh Cecal Wall and Cecal Contents, and pH of the Cecal Contents (experiment 1)

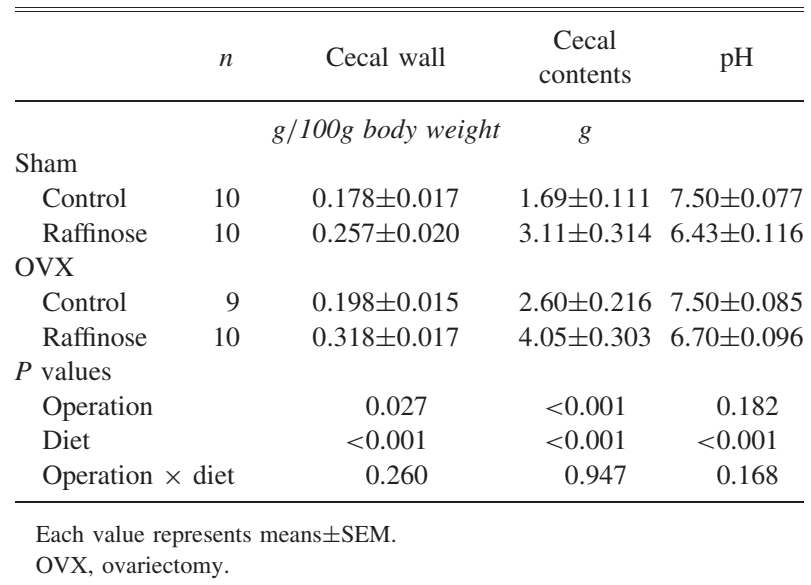

\section{$\square$ Control}

A

B

$\square$ Raffinose

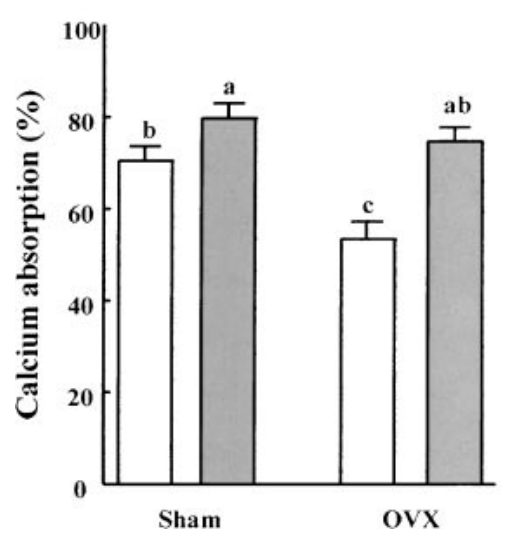

Fig. 1. Calcium Absorption Rate (A) and Magnesium Absorption Rate (B) in Sham-operated and OVX Rats (experiment 1).

Each value represents the mean $\pm \operatorname{SEM}(n=9$ in the ovariectomy and control group; $n=10$ in the two sham groups and in the ovariectomy and raffinose group). $P$-values estimated by two-way analysis of variance were less than 0.001 (A), 0.419 (B) for operation, 0.001 (A, B) for diet, and $0.032(\mathrm{~A}), 0.294$ (B) for operation $\times$ diet. Values not sharing a common letter are significantly different, $P<0.05$. OVX, ovariectomy. 
Table 4. The Total and Soluble Calcium Pool and the Ratio of Soluble Calcium in the Cecal Contents (experiment 1)

\begin{tabular}{|c|c|c|c|c|}
\hline & $n$ & $\begin{array}{c}\text { Total Ca } \\
\text { pool }\end{array}$ & $\begin{array}{c}\text { Soluble } \mathrm{Ca} \\
\text { pool }\end{array}$ & Soluble Ca \\
\hline & & \multicolumn{2}{|c|}{$\mu \mathrm{mol} / \mathrm{cecal}$ content } & $\%$ \\
\hline \multicolumn{5}{|l|}{ Sham } \\
\hline Control & 10 & $204 \pm 26.9$ & $19.5 \pm 2.69$ & $10.6 \pm 1.33$ \\
\hline Raffinose & 10 & $239 \pm 40.1$ & $37.7 \pm 7.63$ & $17.8 \pm 3.03$ \\
\hline \multicolumn{5}{|l|}{ ovX } \\
\hline Control & 9 & $374 \pm 38.7$ & $20.0 \pm 4.17$ & $5.8 \pm 1.29$ \\
\hline Raffinose & 10 & $355 \pm 58.6$ & $63.1 \pm 11.35$ & $21.2 \pm 3.85$ \\
\hline \multicolumn{5}{|l|}{$P$ values } \\
\hline Operation & & 0.003 & 0.098 & 0.792 \\
\hline Diet & & 0.857 & $<0.001$ & $<0.001$ \\
\hline Operation $\times$ diet & & 0.544 & 0.111 & 0.140 \\
\hline
\end{tabular}

Each value represents means \pm SEM.

Soluble $\mathrm{Ca}$ in the cecal content $(\%)=100 \times($ soluble $\mathrm{Ca}$ pool $/$ total $\mathrm{Ca}$ pool).

OVX, ovariectomy

(Table 4). The soluble calcium pool and solubility rate of the raffinose diet group were higher than those of the control group. Concentrations of SCFA and other organic acids in the cecal contents are shown in Table 5. Butyrate and lactate concentrations were higher in rats fed the raffinose diet than in rats fed the control diet. In the sham rats, lactate concentration was 20 -fold higher in rats fed the raffinose diet than in rats fed the control diet. There were no inter-group differences in acetate or succinate concentrations.

\section{Experiment 2}

There were no differences in mean final body weight or food intake between groups. The calcium absorption rate in the OVX-sham rats fed the raffinose diet was higher than that in the OVX-sham rats fed the control diet, as in experiment 1 (Fig. 2A). In the OVXcecocolonectomized rats, the calcium absorption rate was not increased by feeding with the raffinose diet. In the raffinose-fed groups, the absorption rate was much lower in the cecocolonectomized rats than in the sham rats; however, there were no observed differences between in sham and cecocolonectomized rats fed the control diet. The magnesium absorption was lower in the OVX-cecocolonectomized rats than in the OVX-sham rats (Fig. 2B). There were no differences in magnesium absorption rates between the control and the raffinose diet in both the OVX-sham and OVX-cecocolonectomized rats.

\section{Discussion}

In this study, we demonstrated that ingestion of raffinose, an indigestible oligosaccharide, increased the calcium and magnesium absorption rates in OVX and sham-operated rats (Fig. 1). The observed decrease in calcium absorption caused by ovariectomy agrees with the results of previous studies, which have reported that estrogen stimulates duodenal calcium absorption via an estrogen receptor, ${ }^{9)}$ and estrogen deficiency impairs calcium absorption in the small intestine. ${ }^{5,8,14)}$ Calcium malabsorption has been implicated as a risk factor for postmenopausal osteoporosis. ${ }^{1,2)}$ Low dietary calcium levels also accelerate osteoporosis, and postmenopausal women tend toward a low calcium intake. ${ }^{3,4)}$ In this study, we adopted a $3.0 \mathrm{~g} \mathrm{Ca} / \mathrm{kg}$ diet, which is the minimum requirement of calcium carbonate in rats. ${ }^{8)}$ Under this condition, ingestion of raffinose promoted efficient calcium absorption. Especially, in the case of OVX rats, increasing calcium absorption by feeding raffinose was higher than that of sham rats. This result suggests that ingestion of raffinose prevented calcium malabsorption in OVX rats. In this study, there were considerable differences between calcium absorption rates of OVX rats in experiments 1 and 2. In experiment 2, OVX-sham rats underwent transsection of the terminal ileum and reanastomosis. This operation might affect calcium absorption in OVX-sham rats because if a part of the intestinal tract at the operation point becomes narrow, transit time of the chyme might be slowed and this alteration may increase in the calcium absorption. On the other hand, magnesium absorption was not influenced by ovariectomy (Fig. 1B). Magnesium is absorbed throughout the intestine and especially the small intestine is the main part, but the large intestine is

Table 5. Concentrations of SCFA and Other Organic Acids in the Cecal Contents (experiment 1)

\begin{tabular}{|c|c|c|c|c|c|c|}
\hline & $n$ & Acetate & Propionate & Butyrate & Succinate & Lactate \\
\hline & \multicolumn{6}{|c|}{$\mu \mathrm{mol} / \mathrm{g}$ cecal contents } \\
\hline \multicolumn{7}{|l|}{ Sham } \\
\hline Control & 10 & $29.5 \pm 1.94$ & $8.28 \pm 0.93^{\mathrm{a}}$ & $3.97 \pm 0.61$ & $4.14 \pm 1.80$ & $1.67 \pm 0.22^{\mathrm{b}}$ \\
\hline Raffinose & 10 & $27.9 \pm 4.46$ & $2.62 \pm 0.98^{\mathrm{b}}$ & $6.54 \pm 1.51$ & $1.65 \pm 0.79$ & $32.9 \pm 7.82^{\mathrm{a}}$ \\
\hline \multicolumn{7}{|l|}{ OVX } \\
\hline Control & 9 & $24.4 \pm 1.33$ & $7.73 \pm 0.62^{\mathrm{a}}$ & $3.58 \pm 0.23$ & $4.38 \pm 1.21$ & $1.61 \pm 0.51^{\mathrm{b}}$ \\
\hline Raffinose & 10 & $27.1 \pm 1.18$ & $7.75 \pm 0.78^{a}$ & $9.59 \pm 1.34$ & $1.78 \pm 0.66$ & $14.2 \pm 3.03^{\mathrm{a}}$ \\
\hline \multicolumn{7}{|l|}{$P$ values } \\
\hline Operation & & 0.258 & 0.011 & 0.220 & 0.879 & 0.033 \\
\hline Diet & & 0.821 & 0.002 & $<0.001$ & 0.042 & $<0.001$ \\
\hline Operation $\times$ diet & & 0.420 & 0.002 & 0.117 & 0.965 & 0.035 \\
\hline
\end{tabular}

Each value represents means \pm SEM. Values in a column not sharing a superscript differ significantly, $P<0.05$ by ANOVA.

SCFA, short-chain fatty acids; OVX, ovariectomy. 


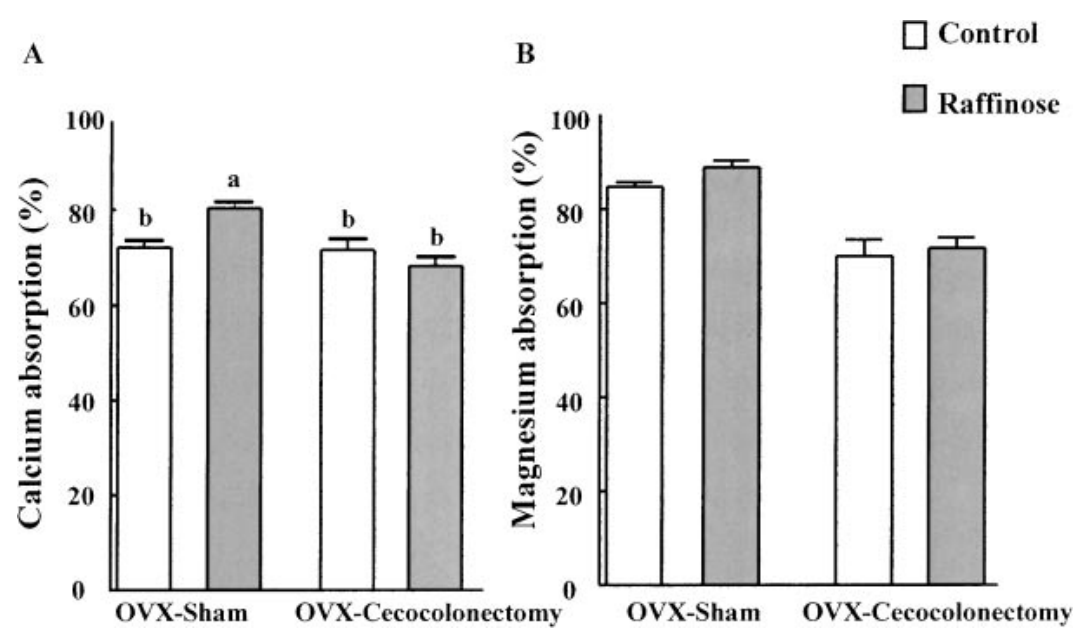

Fig. 2. Calcium Absorption Rate (A) and Magnesium Absorption Rate (B) in OVX Rats with or without Cecocolonectomy (experiment 2). Each value represents the mean $\pm \operatorname{SEM}(n=8)$. $P$-values estimated by two-way analysis of variance were less than 0.001 (A, B) for operation, 0.146 (A), 0.130 (B) for diet, and 0.002 (A), 0.657 (B) for operation $\times$ diet. Values not sharing a common letter are significantly different, $P<0.05$. OVX, ovariectomy.

also important for magnesium absorption in rats. ${ }^{16,26)}$ This study showed that the magnesium absorption rate was impaired by cecocolonectomy in rats, although it was small (Fig. 2B). This result suggests that magnesium is also absorbed efficiently in the distal parts of the intestine.

Canceling the promotive effect of raffinose by removal of the large intestine (Fig. 2) reveals that the small intestine does not contribute to the action of raffinose. Rather, the large intestine alone is involved in the beneficial effects of raffinose. In this study, we showed that ingestion of raffinose led to a lower cecal $\mathrm{pH}$ (Table 3), a greater pool of soluble calcium in the cecal contents (Table 4), and increased concentrations of SCFA, particularly butyrate and lactate, in rats (Table 5). These results suggest that ingestion of raffinose reduced cecal $\mathrm{pH}$ by production of organic acids, especially lactate. And that this acidification of the cecal contents induces the solubilization of calcium. An increase in the calcium solubility is involved in the increased calcium absorption. Moreover, the presence of SCFA is one of the promotive factors for calcium absorption in the large intestine. ${ }^{18,19)}$

Calcium absorption in the small intestine is strictly regulated by endogenous factors such as parathyroid hormone and 1, 25-dihydroxycholecalciferol. ${ }^{27)}$ When small-intestinal calcium absorption was decreased, the large intestine compensated for the deficiency in calcium absorption. ${ }^{10)}$ In cases of lower calcium intake and insufficient calcium absorption in the small intestine, calcium absorption in the large intestine is important to maintain calcium homeostasis. This study demonstrates that ingestion of raffinose promotes calcium absorption in the large intestine in OVX rats. Guidelines for dietary calcium intake have been proposed for minimizing the risk of osteoporosis; ${ }^{1,2}$ ) however, the calcium intake in Japan is lower than the dietary reference intake of calcium. ${ }^{3,4)}$ In this situation, the addition of raffinose as a natural food in the diet may effectively promote calcium absorption, especially in menopausal women who have impaired calcium absorption in the small intestine. Further studies are required to examine the effects of raffinose on calcium absorption in humans.

In conclusion, ingestion of raffinose increased calcium and magnesium absorption in OVX and shamoperated rats. In the case of OVX rats, raffinose feeding prevented calcium malabsorption completely. The promotive effect of raffinose on calcium absorption was abolished by cecocolonectomy. The large intestine is involved in the beneficial effects of raffinose.

\section{References}

1) NIH Consensus Development Panel on Optimal Calcium Intake, Optimal calcium intake. J. Am. Med. Assoc., 272, 1942-1948 (1994).

2) Prentice, A., What are the dietary requirements for calcium and vitamin D? Calcif. Tissue Int., 70, 83-88 (2002).

3) Fujita, T., Clinical guidelines for the treatment of osteoporosis in Japan. Calcif. Tissue Int., 59, S34-S37 (1996).

4) Uenishi, K., Ishida, H., Kamei, A., Shiraki, M., Ezawa, I., Goto, S., Fukuoka, H., Hosoi, T., and Orimo, H., Calcium requirement estimated by balance study in elderly Japanese people. Osteoporos. Int., 12, 858-863 (2001).

5) O'Loughlin, P. D., and Morris, H. A., Oestrogen deficiency impairs intestinal calcium absorption in the rat. J. Physiol., 511, 313-322 (1998).

6) Holzherr, M. L., Retallack, R. W., Gutteridge, D. H., Price, R. I., Faulkner, D. L., Wilson, S. G., Will, R. K., Stewart, G. O., Stuckey, B. G., Prince, R. L., Criddle, R. A., Kent, G. N., Bhagat, C. I., Dhaliwal, S. S., and Jamrozik, K., Calcium absorption in postmenopausal 
osteoporosis: benefit of HRT plus calcitriol, but not HRT alone, in both malabsorbers and normal absorbers. Osteoporos. Int., 11, 43-51 (2000).

7) Kalu, D. N., The ovariectomized rat model of postmenopausal bone loss. Bone Miner., 15, 175-191 (1991).

8) Mitamura, R., Hara, H., Aoyama, Y., and Chiji, H., Supplemental feeding of difructose anhydride III restores calcium absorption impaired by ovariectomy in rats. J. Nutr., 132, 3387-3393 (2002).

9) Bolscher, M., Netelenbos, J. C., Barto, R., Buuren, L. M., and Vijgh, W. J., Estrogen regulation of intestinal calcium absorption in the intact and ovariectomized adult rat. J. Bone Miner. Res., 14, 1197-1202 (1991).

10) Shiga, K., Hara, H., and Kasai, T., The large intestine compensates for insufficient calcium absorption in the small intestine in rats. J. Nutr. Sci. Vitaminol., 44, 737744 (1998).

11) Levrat, M. A., Behr, S. R., Remesy, C., and Demigne, C., Effects of soybean fiber on cecal digestion in rats previously adapted to a fiber-free diet. J. Nutr., 121, 672-678 (1991).

12) Hara, H., Suzuki, T., Kasai, T., Aoyama, Y., and Ohta, A., Ingestion of guar gum hydrolysate, a soluble fiber, increases calcium absorption in totally gastrectomized rats. J. Nutr., 129, 39-45 (1999).

13) Roberfroid, M. B., Concepts in functional foods: the case of inulin and oligofructose. J. Nutr., 129, 1398S-1401S (1999).

14) Mitamura, R., Hara, H., Aoyama, Y., Takahashi, T., and Furuta, H., Ingestion of water-soluble soybean fiber prevents osteopenia and hypercholesterolemia induced by ovariectomy in rats. J. Agric. Food Chem., 51, 10851089 (2003).

15) Chonan, O., Matsumoto, K., and Watanuki, M., Effect of galactooligosaccharides on calcium absorption and preventing bone loss in ovariectomized rats. Biosci. Biotechnol. Biochem., 59, 236-239 (1995).

16) Ohta, A., Ohtsuki, M., Baba, S., Adachi, T., Sakata, T., and Sakaguchi, E., Calcium and magnesium absorption from the colon and rectum are increased in rats fed fructooligosaccharides. J. Nutr., 125, 2417-2424 (1995).

17) Hara, H., Suzuki, T., Kasai, T., Aoyama, Y., and Ohta, A., Ingestion of guar-gum hydrolysate partially restores calcium absorption in the large intestine lowered by suppression of gastric acid secretion in rats. Br. J. Nutr., 81, 315-321 (1999).

18) Trinidad, T. P., Wolever, T. M., and Thompson, L. U., Effects of calcium concentration, acetate, and propionate on calcium absorption in the human distal colon. Nutrition, 15, 529-533 (1999).

19) Mineo, H., Hara, H., and Tomita, F., Short-chain fatty acids enhance diffusional ca transport in the epithelium of the rat cecum and colon. Life Sci., 69, 517-526 (2001).

20) Nagura, T., Hachimura, S., Hashiguchi, M., Ueda, Y., Kanno, T., Kikuchi, H., Sayama, K., and Kaminogawa, S., Suppressive effect of dietary raffinose on T-helper 2 cell-mediated immunity. Br. J. Nutr., 88, 421-426 (2002).

21) Suzuki, T., Hara, H., Kasai, T., and Tomita, F., Effects of difructose anhydride III on calcium absorption in small and large intestines of rats. Biosci. Biotechnol. Biochem., 62, 837-841 (1998).

22) Mineo, H., Hara, H., Kikuchi, H., Sakurai, H., and Tomita, F., Various indigestible saccharides enhance net calcium transport from the epithelium of the small and large intestine of rats in vitro. J. Nutr., 131, 3243-3246 (2001).

23) Reeves, P. G., Nielsen, F. H., and Fahey, G. J., AIN-93 purified diets for laboratory rodents: final report of the American Institute of Nutrition ad hoc writing committee on the reformulation of the AIN-76A rodent diet. $J$. Nutr., 123, 1939-1951 (1993).

24) Hayashi, K., Hara, H., Asvarujanon, P., Aoyama, Y., and Luangpituksa, P., Ingestion of insoluble dietary fibre increased zinc and iron absorption and restored growth rate and zinc absorption suppressed by dietary phytate in rats. Br. J. Nutr., 86, 443-451 (2001).

25) Duncan, D. B., Multiple range and multiple $F$ test. Biometrics, 11, 1-42 (1955).

26) Shiga, K., Hara, H., Suzuki, T., Nishimukai, M., Konishi, A., and Aoyama, Y., Massive large bowel resection decreases bone strength and magnesium content but not calcium content of the femur in rats. Nutrition, 17, 397-402 (2001).

27) Bronner, F., and Pansu, D., Nutritional aspects of calcium absorption. J. Nutr., 129, 9-12 (1999). 